Article

\title{
Photostabilizing Efficiency of Acrylic-based Bamboo Exterior Coatings Combining Benzotriazole and Zinc Oxide Nanoparticles
}

\author{
Fei Rao ${ }^{1,2,3}$, Yahui Zhang ${ }^{2}$, Minzhen Bao ${ }^{1,3}$, Zhiyuan Zhang ${ }^{4}$, Yongjie Bao ${ }^{1,2,3}$, Neng Li $^{1,2, *}$, \\ Yuhe Chen ${ }^{1,2, *}$ and Wenji Yu ${ }^{1,2}$ \\ 1 Department of Efficient Utilization of Bamboo and Wood, China National Bamboo Research Center, \\ Wenyi Road 310, Hangzhou 310012, China \\ 2 Department of Wood-based Panels and Adhesives, Research Institute of Wood Industry, Chinese Academy \\ of Forestry, Xiang Shan Road, Haidian, Beijing 100091, China \\ 3 Department of Efficient Utilization of Bamboo and Wood, Key Laboratory of High Efficient Processing of \\ Bamboo of Zhejiang Province, Wenyi Road 310, Hangzhou 310012, China \\ 4 Department of Aquatic Botany, Zhejiang Humanities Landscape Co., Ltd., Tianmushan Road 223, \\ Hangzhou 310012, China \\ * Correspondence: lineng@caf.ac.cn (N.L.); yuhec@caf.ac.cn (Y.C.)
}

Received: 18 July 2019; Accepted: 20 August 2019; Published: 22 August 2019

\begin{abstract}
Long-term exposure to ultraviolet (UV) light can degrade and discolor bamboo; thus, coatings to protect it from UV exposure are required, especially for outdoor use. Benzotriazole (BTZ) and zinc oxide nanoparticles (NZnO) are organic and inorganic $\mathrm{UV}$ absorbers commonly used in UV shielding coatings. This study investigated the photostabilizing efficiency of acrylic-based bamboo exterior coatings using a combination of BTZ and NZnO. Different film formulations covering bamboo substrates were irradiated with artificial UV light for $500 \mathrm{~h}$ to accelerate aging. The UV-shielding effect on bamboo beneath various films was determined by CIELAB color space and Fourier transform infrared (FTIR) analysis. The film effectiveness was analyzed by scanning electron microscopy, wettability, UV-vis spectroscopy, and FTIR-attenuated total reflection (ATR) spectroscopy. Films containing BTZ provided higher resistance to photodegradation and more effectively inhibited photodiscoloration of the bamboo substrates than those prepared solely with $\mathrm{NZnO}$. After $500 \mathrm{~h}$ of UV irradiation, the BTZ-NZnO film containing $2 \mathrm{wt} \% \mathrm{BTZ}$ and $1 \mathrm{wt} \% \mathrm{NZnO}$ showed the best coating performance. Strong synergistic effects were detected in the BTZ-NZnO coatings, particularly for the 2:1 ratio formulation. This study also demonstrated the potential of combining BTZ and $\mathrm{NZnO}$ as additives for developing stable, effective UV-shielding bamboo exterior coatings for outdoor applications.
\end{abstract}

Keywords: bamboo; benzotriazole; zinc oxide nanoparticles; photostability; synergistic; outdoor

\section{Introduction}

Bamboo is an ecologically sustainable lignocellulosic material with reliable processing performance and is widely used for building, decorating, and flooring. However, bamboo and its products undergo environmental degradation without protective treatment, which results in surface photodiscoloration $[1,2]$. In addition, this degradation causes cracks in the cells' walls [3], considerably affects lignin and hemicelluloses [4], and gradually decreases the mechanical properties of bamboo [5]. Ultraviolet (UV) light has a short wavelength, and its energy is high enough to cleave many critical functional groups and linkages in bamboo components (e.g., lignin, cellulose, and hemicellulose) [6]. Moreover, lignin itself promotes such photochemical reactions $[7,8]$. 
Transparent or translucent coatings containing UV absorbers satisfactorily maximize the retention of bamboo's aesthetic value (e.g., the natural color and the beautiful texture) and mitigate surface photodegradation of bamboo for outdoor applications. Benzotriazole (BTZ) is the most important organic UV absorber for many transparent coatings because of its high UV but low visible-light absorbance $[9,10]$. A UV-curable coating containing 5\% BTZ successfully protected outdoor bamboo scrimber and hindered the photodegradation of the substrate and the coating itself [11]. Another study determined that the critical loading of BTZ for a high degree of UV shielding was $1.82 \pm 0.05 \mathrm{~g} / \mathrm{m}^{2}$ [12]. Furthermore, the effects of BTZ in such coatings are synergistic, as BTZ effectively reduces photo-oxidation while improving the elastic properties of the acrylic binder [13]. However, its main disadvantage is that it degrades during long-term illumination, thereby decreasing its ability to absorb UV light $[9,14]$. Meanwhile, ZnO nanoparticles $(\mathrm{NZnO})$ in coatings offer advantages such as broad UV absorption, low refractive index, and non-degradability. The influence of the $\mathrm{NZnO}$ concentration and film thickness on protection from UV irradiation was previously investigated, and $2.0 \mathrm{~g} / \mathrm{m}^{2} \mathrm{NZnO}$ was found to block $>99 \%$ UV radiation [15]. However, the photocatalytic activity and dispersion stability of $\mathrm{NZnO}$ must be considered when it is added to coating formulations as an inorganic UV absorber [16-18]. Therefore, researchers attempted to modify the surface of NZnO. For instance, silica-coated NZnO significantly improves the UV resistance of the coating, but NZnO may also aggregate within the coating [16]. Silane-modified NZnO does not aggregate, but exhibits reduced UV-vis absorption capacity [19]. Similarly, grafting polystyrene onto the $\mathrm{NZnO}$ surface improves dispersion but reduces UV-vis absorption, thereby decreasing the photocatalytic activity of the $\mathrm{NZnO}$ [17]. Nair et al. prepared a stable dispersion of $\mathrm{NZnO}$ in propylene glycol using ultrasonication [20]. However, the addition of BTZ or NZnO in the coating revealed shortcomings, while their advantages were not fully realized [9]. During aging, BTZ decomposed and led to decreased absorbance, while $\mathrm{NZnO}$ aggregated [9]. Therefore, some additives were applied to the wood surface treatment [21], and the strongest synergistic effect was confirmed when BTZ with hindered amine light stabilizers (HALS, Tinuvin 5151), in combination with $\mathrm{TiO}_{2}$ and $\mathrm{NZnO}$, were mixed [22]. Our previous study found that the combination of $\mathrm{BTZ}$ and $\mathrm{NZnO}$ in acrylic coatings overcame their respective deficiencies and realized the full advantages associated with the addition of both $\mathrm{BTZ}$ and $\mathrm{NZnO}$ in order to protect bamboo substrates against UV light. Interestingly, a synergistic effect between the two was identified [9]; however, this synergism has not been completely elucidated and the ratio of these two absorbers must be optimized. Moreover, the use of these complementary and mutually reinforcing strategies could be widely applied to design a novel class of transparent, efficient UV-shielding materials that are photostable.

This study aims to optimize and characterize a transparent, acrylic-based protective coating to impart high photostability on bamboo. Thus, films with four different combinations of 2-(2-hydroxy3-tert-butyl-5-methyl-phenyl)-5-chlorinated BTZ and NZnO at different ratios and films containing only BTZ or NZnO were prepared by physical blending. Bamboo samples covered with these different films were prepared for UV-accelerated aging. The photostability of these films was examined by comparing the discoloration and chemical changes of the underlying bamboo surface. Furthermore, the effect of different BTZ-NZnO ratios on the performance of the films was evaluated based on the coating lifetime. To understand the protection mechanism of UV absorbers in the film-coated bamboo, scanning electron microscopy (SEM), wettability measurements, and UV-visible (vis) and Fourier transform infrared-attenuated total reflection (FTIR-ATR) spectroscopies were carried out on the free films.

\section{Materials and Methods}

\subsection{Sample Preparation for Accelerated Aging}

Samples to simulate the long-term aging (i.e., accelerated aging) of coated bamboo included two parts: (Part 1) the bamboo substrate and (part 2) the free film prepared on quartz glass using different 
coating formulations (Figure 1) [23-25]. Sections of the free films were then placed on the bamboo near the green surface prior to UV irradiation.

\subsubsection{Bamboo Substrates (Sample B)}

Bamboo blocks without knots, periderm, or inner tissue, measuring $40 \mathrm{~mm} \times 15 \mathrm{~mm} \times 5 \mathrm{~mm}$ (length $\times$ width $\times$ height), were obtained from the same section of bamboo (Phyllostachys pubescens Mazel) culm. Subsequently, the specimens were sanded using 120-grit sand paper and conditioned to a moisture content of $\sim 12 \%$.

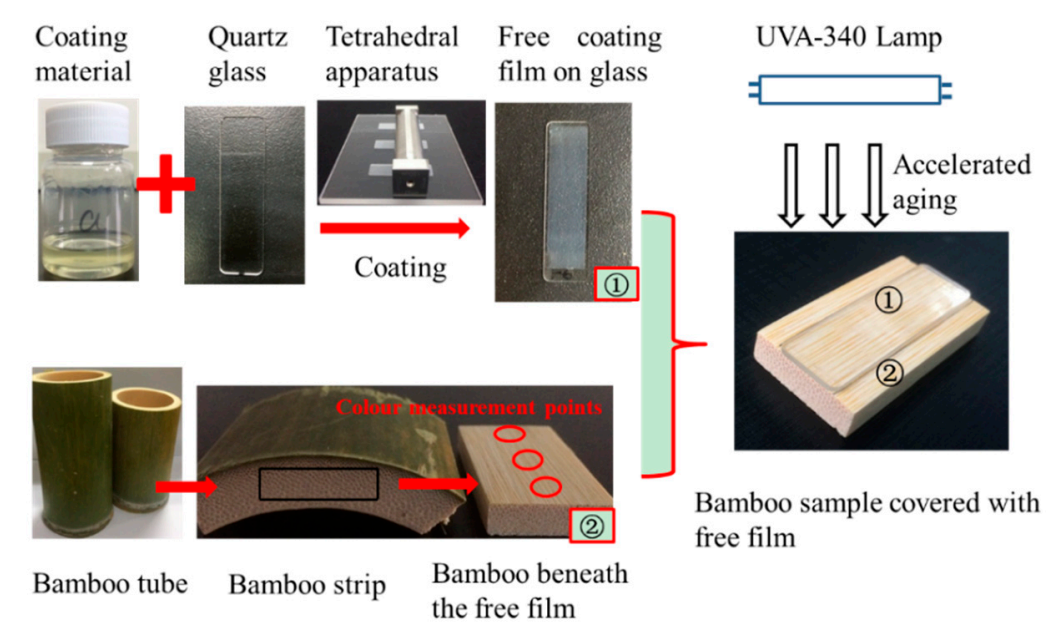

Figure 1. Preparation of samples for the accelerated aging of coated bamboo.

\subsubsection{Free Film Coatings (Sample C)}

The acrylic clear-coat resin composition and UV absorbers were the same as those used in our previous study [9]. Eight coating formulations were prepared, as listed in Table 1, including a clear-coat resin without UV absorbers as the control (blank), coatings containing only BTZ or NZnO, and five formulations containing both absorbers in different ratios (Table 1). The free films were prepared on quartz glass substrates $(45 \mathrm{~mm} \times 12.5 \mathrm{~mm} \times 1.0 \mathrm{~mm}$ ) using an automatic film applicator (BUG 219, Biuged Laboratory Instrument Co., Ltd., Guangzhou, China) equipped with tetrahedral wet film preparation apparatus (SZQ, AI Testing Instrument Co., Ltd., Taizhou, China), resulting in $\sim 75 \mu \mathrm{m}$ thick films covering an area of $40 \mathrm{~mm} \times 10 \mathrm{~mm}$. After curing at $25^{\circ} \mathrm{C}$ for $24 \mathrm{~h}$, the weight of the dry film was approximately $0.0050 \pm 0.0004 \mathrm{~g}$, and a portion of this dry film was peeled off for subsequent experiments.

Table 1. Coating formulations used in this study.

\begin{tabular}{lllllll}
\hline $\begin{array}{c}\text { Coating } \\
\text { Formulation }\end{array}$ & $\begin{array}{l}\text { BTZ } \\
(\mathbf{w t} \%)\end{array}$ & $\begin{array}{l}\text { NZnO } \\
(\mathbf{w t} \%)\end{array}$ & $\begin{array}{l}\text { Content Ratio } \\
(\text { BTZ: NZnO) }\end{array}$ & $\begin{array}{l}\text { Additive } \\
\text { Amount (g) }\end{array}$ & $\begin{array}{l}\text { Anhydrous } \\
\text { Alcohol (g) }\end{array}$ & $\begin{array}{l}\text { Clear-Coat } \\
\text { Resin (g) }\end{array}$ \\
\hline Control (blank)-C * & 0 & 0 & - & 0 & 2.60 & 17.40 \\
BTZ-C $^{*}$ & 3.00 & 0 & - & $0.6^{\mathrm{a}}$ & 2.00 & 17.40 \\
NZnO-C $^{*}$ & 0 & 3.00 & - & $3^{\mathrm{b}}$ & 0 & 17.00 \\
B3Z1-C & 2.25 & 0.75 & $3: 1$ & $0.45^{\mathrm{a}}+0.75^{\mathrm{b}}$ & 1.40 & 17.40 \\
B2Z1-C & 2.00 & 1.00 & $2: 1$ & $0.40^{\mathrm{a}}+1.00^{\mathrm{b}}$ & 1.20 & 17.40 \\
B1Z1-C & 1.50 & 1.50 & $1: 1$ & $0.30^{\mathrm{a}}+1.50^{\mathrm{b}}$ & 0.80 & 17.40 \\
B1Z2-C & 1.00 & 2.00 & $1: 2$ & $0.20^{\mathrm{a}}+2.00^{\mathrm{b}}$ & 0.40 & 17.40 \\
B1Z3-C & 0.75 & 2.25 & $1: 3$ & $0.15^{\mathrm{a}}+2.25^{\mathrm{b}}$ & 0.20 & 17.40 \\
\hline
\end{tabular}

${ }^{*}$ Data for control (blank), B1Z1, and single-component ultraviolet (UV) absorber coatings are from [9]. ${ }^{\text {a }}$ refers to benzotriazole (BTZ) powder; ${ }^{b}$ refers to $20 \mathrm{wt} \% \mathrm{NZnO}$ dispersed in isopropanol. 


\subsection{Artificial Accelerated Aging Test}

Samples were fixed in stainless steel holders and irradiated with UV light using an accelerated UV weathering test box (Hangzhou Nine Ring Fu Da Industrial Co., Ltd., Hangzhou, China). To more closely resemble natural illumination, the simulated irradiance level of the UVA-340 lamp was set to $25 \mathrm{~W} / \mathrm{m}^{2}$ [26]. The aging procedure was interrupted every $10 \mathrm{~h}$ to monitor color changes.

\subsection{Characterization}

\subsubsection{Scanning Electron Microscopy (SEM) Imaging}

The structures of unaged and $500 \mathrm{~h}$-aged free films were observed using an SEM system (S-3400N, Hitachi, Tokyo, Japan), which was operated at an accelerating voltage of $15 \mathrm{kV}$. Prior to the SEM imaging process, the films were coated with gold/palladium in a vacuum sputter coater.

\subsubsection{Contact Angle Measurements}

Deionized water was dispensed on the free film specimens using the sessile drop method using a contact angle analyzer (DSA 100, Krüss, Hamburg, Germany). The initial contact angle $\left(\theta_{\mathrm{i}}\right)$ measurements were recorded as soon as the test droplets touched the sample surface, typically within 0 to 3 frames ( 1 frame $\approx 19.2 \mathrm{~ms}$ ). The contact angle of each liquid was measured in triplicate in the same zone of each free film and the mean value was calculated. Data were collected within 90 frames from the start of the measurements. The equilibrium contact angle $\left(\theta_{\mathrm{e}}\right)$, penetration, and spreading rate constant $(K$-value) were calculated following previously published methods $[27,28]$.

\subsubsection{UV-vis Spectroscopy of Free Films}

The UV-vis spectra of free films were recorded on a UV-vis spectrophotometer (UV-2550 PC, Shimadzu Suzhou Instruments Mfg. Co., Ltd., Suzhou, China). Quartz slides were sized to exactly fit the sample cell of the spectrophotometer. Spectra were recorded at wavelengths of $200-800 \mathrm{~nm}$ in $1 \mathrm{~nm}$ steps.

\subsubsection{Discoloration Measurement of Underlying Bamboo}

Precisely defined points on the underlying bamboo surface were measured three times using a Konica Minolta CR-10 system equipped with a D65 illumination source (Tokyo, Japan) in accordance with the Commission Internationale de I'Eclairage (CIE) $L^{*} a^{*} b^{*}$ parameters (ASTM D2244-14 [29], CIE 1976). The color data for each film were collected for three bamboo specimens and mean values were determined. The total color difference $\left(\Delta E^{*}\right)$ was calculated according to the following equation [29]:

$$
\Delta E^{*}=\sqrt{\left(L_{t}^{*}-L_{o}^{*}\right)^{2}+\left(a_{t}^{*}-a_{o}^{*}\right)^{2}+\left(b_{t}^{*}-b_{o}^{*}\right)^{2}}
$$

where subscripts $o$ and $t$ denote values before and after UV exposure for $t$ hours, respectively. The efficiencies of additive-containing coatings ( $\eta_{\text {additive }}$ ) [30] for the inhibition of bamboo photodiscoloration were defined as

$$
\eta_{\text {additive }}=\frac{\Delta E_{\text {Blank }}^{*}-\Delta E_{\text {additive }}^{*}}{\Delta E_{\text {Blank }}^{*}} \times 100 \%
$$

\subsubsection{Evaluation of One- and Two-Component UV Absorber Effects}

Changes in the surface color of the underlying bamboo were observed with increasing UV irradiation time. Because color differences perceivable by the naked eye correspond to $\Delta E^{*}=3 \sim 6[2,31]$, the lifetime of a coating was defined as the UV irradiation time required for $\Delta E^{*}$ to reach a value of 
6. The protection time is the time during which no color changes were observable by the naked eye. A longer protection time indicated a more efficient coating.

Based on the definition of synergistic and antagonistic effects by Gugumus [32], lifetime increment parameters $(\Delta T)$ were calculated to quantify the additive effect for a combination of two UV absorbers.

$$
\Delta T=T_{\mathrm{BTZ}+\mathrm{NZnO}}-\left(r_{\mathrm{BTZ}} T_{\mathrm{BTZ}}+r_{\mathrm{NZnO}} T_{\mathrm{NZnO}}\right),
$$

where $T_{\mathrm{BTZ}}$ and $T_{\mathrm{NZnO}}$ designate the lifetimes of coatings containing individual absorbers $\mathrm{BTZ}$ and $\mathrm{NZnO}$, respectively, while $T_{\mathrm{BTZ}+\mathrm{NZnO}}$ represents the lifetime of a two-component (BTZ-NZnO) absorber film. In Equation (3), $r_{\mathrm{BTZ}}$ and $r_{\mathrm{NZnO}}$ designate the relative amounts of components BTZ and $\mathrm{NZnO}$ in the two-component film, respectively. Synergism was indicated when $\Delta T>0$, while $\Delta T<0$ indicated antagonism. Moreover, a purely additive effect was also possible, corresponding to $\Delta T=0$.

\subsubsection{Fourier Transform Infrared (FTIR) Spectroscopy}

FTIR spectra were measured directly from free film surfaces using ATR with a spectral resolution of $4 \mathrm{~cm}^{-1}$ at $64 \mathrm{scans} /$ measurement in the mid-infrared (IR) region $\left(4000-400 \mathrm{~cm}^{-1}\right)$ using a Nicolet iS10 spectrophotometer (Thermo Scientific, Waltham, MA, USA).

A sample of bamboo surface layer powder $(1 \mathrm{mg})$ was mixed with $99 \mathrm{mg}$ of $\mathrm{KBr}$ and pressed into pellets at $30 \mathrm{MPa}$ for $2 \mathrm{~min}$ for FTIR analysis. FTIR spectra were recorded using the Nicolet iS10 spectrophotometer in absorbance mode in the range of $4000-400 \mathrm{~cm}^{-1}$. In total, each sample was scanned 64 times at a resolution of $4 \mathrm{~cm}^{-1}$. All spectra were first corrected by automatic baseline, then the peak intensity was calculated by peak area using OMNIC software (version 8 , Thermo Nicolet, WI, USA).

\subsection{Statistical Analysis}

Analysis of variance (ANOVA) was performed using the SPSS software package (version 21.0, IBM, New York, NY, USA) and corresponding curves were drawn using OriginLab OriginPro 2016 (version 2016 SR0 b9.3.226, OriginLab Corporation, Northampton, England).

\section{Results and Discussion}

\subsection{Determination of Bamboo Photoprotection from Films}

The UV-shielding capability of coatings with different formulations (including two-component absorbers present in different proportions) was determined by changes in UV-induced surface discoloration and chemical composition of the bamboo substrate underneath the film. The surface color of the underlying bamboo gradually changed with increasing UV irradiation time, as detailed below.

\subsubsection{Surface Discoloration of Underlying Bamboo}

Figure 2 shows the $\Delta E^{*}$ values obtained at different $U V$ irradiation times for bamboo specimens covered with films containing either $\mathrm{BTZ}$ or $\mathrm{NZnO}$ alone, or BTZ-NZnO in different ratios. The $\Delta E^{*}$ of bamboo specimens covered with the control (blank) film was the highest of all the samples, showing a rapid increase during the early stage of aging and a smaller change thereafter. The trend observed for the $\mathrm{NZnO}$ film during aging was similar to that of the control film; the $\Delta E^{*}$ of the $\mathrm{NZnO}$ film after $500 \mathrm{~h}$ of irradiation was 16.08 , which was second only to that of the substrate covered with the control film $\left(\Delta E^{*}=18.14\right)$. The $\Delta E^{*}$ values of the bamboo specimens underneath the films containing BTZ (either alone or combined with $\mathrm{NZnO}$ at various ratios) were between 4.58 (B2Z1-B) and 8.99 (B1Z3-B) after $500 \mathrm{~h}$ of irradiation, which indicated that $\mathrm{BTZ}$ alone or in conjunction with $\mathrm{NZnO}$ inhibited surface discoloration of the substrate at the same concentration ( $3 \mathrm{wt} \%$ ). After a relatively rapid change during the first $100 \mathrm{~h}$ of irradiation, the surface discoloration of the bamboo specimens covered with B3Z1 and B2Z1 films stopped changing, even after an additional $350 \mathrm{~h}$ of irradiation, resulting in final 
total color differences of 6.01 and 4.58, respectively. The bamboo specimens covered with other BTZ films (BTZ, B1Z2, and B1Z3) exhibited varying changes in color after $100 \mathrm{~h}$ of irradiation. Specifically, bamboo under the B1Z3 film exhibited the greatest color change among the BTZ-containing films. Overall, the $\Delta E^{*}$ values of bamboo specimens covered with BTZ-containing films decreased in the following order: B1Z3 (8.99) > B1Z2 (7.24) > BTZ (6.79) > B3Z1 (6.01) > B2Z1 (4.58).

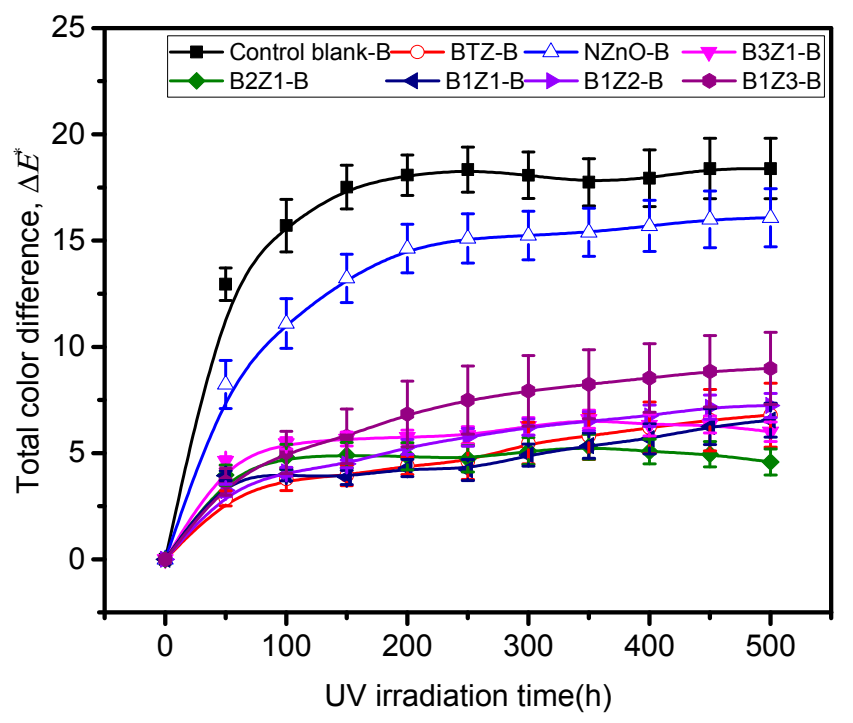

Figure 2. $\Delta E^{*}$ values of bamboo specimens covered with films with different coating formulations as a function of UV-accelerated aging duration.

The photodiscoloration inhibition rate ( $\left.\eta_{\text {additive }}\right)$ was calculated to quantify the amount of UV absorber needed to effectively suppress photochromic behavior toward bamboo specimens covered with modified films (Figure 3). Unsurprisingly, the inhibition efficiency with only $\mathrm{NZnO}$ in the formulation was significantly lower than that of BTZ or BTZ-NZnO combinations. The B2Z1 film most effectively suppressed the discoloration of the underlying bamboo substrate covered. However, a statistical analysis using ANOVA indicated no significant differences between the efficiencies of B3Z1, B1Z2 and BTZ.

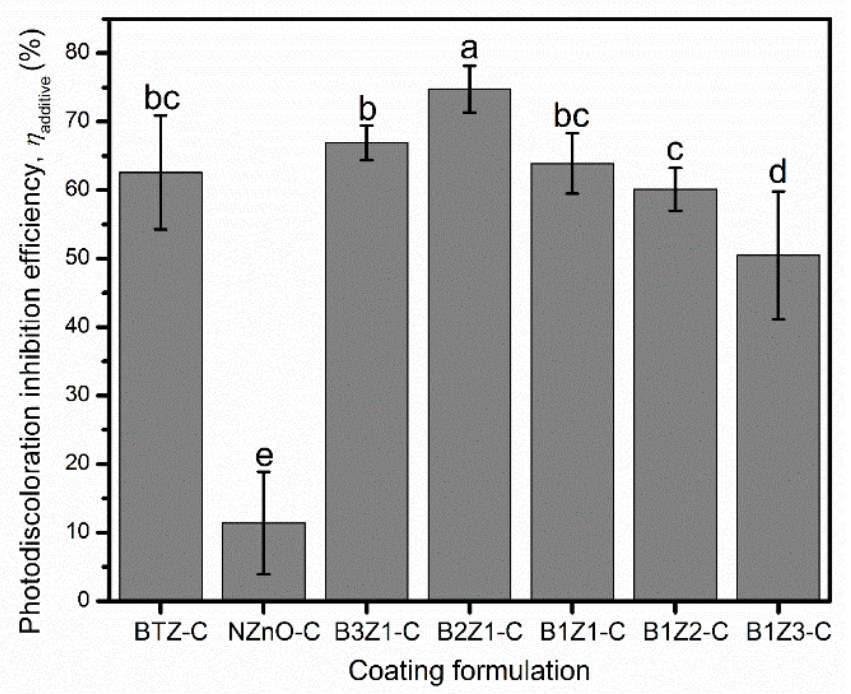

Figure 3. Photodiscoloration inhibition of films containing different ratios of BTZ and NZnO after $500 \mathrm{~h}$ of irradiation. Different lowercase letters within a column indicate significant differences, as determined by Duncan's multiple range test $(p<0.05, \mathrm{~N}=9)$. 


\subsubsection{FTIR Spectra of Underlying Bamboo}

Lignin contains moieties that interact with UV light to form chromophores containing carbonyl groups [6] that absorb $80 \%-95 \%$ of UV light [33], resulting in photodiscoloration [34]. FTIR analysis of pristine bamboo and bamboo beneath various films after $500 \mathrm{~h}$ of accelerated aging was used to analyze chemical changes based on lignin absorption at $1512 \mathrm{~cm}^{-1}$ [24,34]. The intensity of the peak that was associated with carbohydrates at $898 \mathrm{~cm}^{-1}$ (C-H deformation in cellulose) was used as an internal reference because this peak was not significantly affected by exposure time [1]. The relative changes in the lignin/carbohydrate $\left(I_{1512} / I_{898}\right)$ and carbonyl/carbohydrate $\left(I_{1735} / I_{898}\right)$ peak intensity ratios before and after UV irradiation (Figure 4) reflected the degree of lignin degradation and indicated the production of new carbonyl compounds, respectively. Compared with pristine bamboo, the $I_{1512} / I_{898}$ ratio of bamboo beneath the control film decreased to 1.185 , while $I_{1735} / I_{898}$ increased to 22.747 after $500 \mathrm{~h}$ of irradiation. After $500 \mathrm{~h}$ of aging, the bamboo specimens beneath the films containing UV absorber(s) exhibited $I_{1512} / I_{898}$ in the range of 1.590 (NZnO-B) to 3.527 (B3Z1-B) and $I_{1735} / I_{898}$ in the range of 10.735 (B2Z1-B) to 17.878 (B1Z2-B). A comparison of the $I_{1512} / I_{898}$ values of BTZ-containing films with that of pristine bamboo and bamboo beneath the control film revealed that, with films containing BTZ, the degradation of lignin was delayed, especially when the BTZ content was higher than $1 \%$ (BTZ, B3Z1, and B2Z1). Lignin severely degraded on the bamboo surface beneath the film containing only $\mathrm{NZnO}$, which also exhibited discoloration on the macro level (see Figure 2). Carbonyl formation and lignin degradation are closely related for bamboo and wood [1], which could be the reason why the $I_{1735} / I_{898}$ of bamboo specimens beneath the films containing UV absorber(s) was lower than that of the control. The color difference and $I_{1735} / I_{898}$ of the substrate after $500 \mathrm{~h}$ of UV irradiation indicated that the B2Z1 film inhibited carbonyl formation to the greatest extent, which may have resulted from the influence of lignin oxidation and other reactions $[1,6]$. Overall, the B2Z1 film exhibited excellent protection against photodegradation in UV-exposed bamboo surfaces.

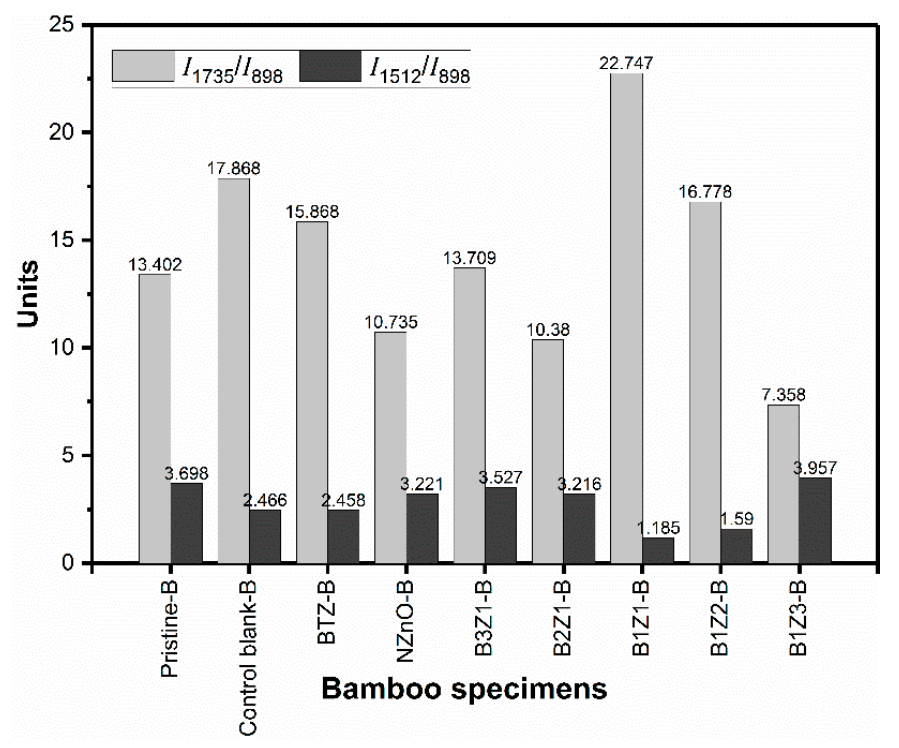

Figure 4. Changes in $I_{1512} / I_{898}$ and $I_{1735} / I_{898}$ values of bamboo beneath various films with different BTZ-NZnO ratios after $500 \mathrm{~h}$ of aging.

\subsubsection{Synergistic Effects of Films on the Photostability of Bamboo Surfaces}

Table 2 lists the lifetimes $(T)$ of films determined from the color changes of the underlying bamboo surface and gives the calculated lifetime increment parameter $(\Delta T)$ of coating films containing different ratios of BTZ and NZnO. The B2Z1 film had the longest lifetime, maintaining high photostability after $500 \mathrm{~h}$ of aging, followed by the B1Z1 and BTZ films. The $\Delta T$ values of all BTZ-NZnO films were greater than 0 , demonstrating that the combination of BTZ and $\mathrm{NZnO}$ resulted in a synergistic effect, 
with this effect being most pronounced for the B2Z1 and B1Z1 films. The total color difference of the bamboo substrate under the B2Z1 film did not reach 6, even after $500 \mathrm{~h}$ of irradiation, suggesting that with increased time, the synergistic effect of the B2Z1 film would become more prominent.

Table 2. $T$ and $\Delta T$ of free films determined from $\Delta E^{*}=6$ of underlying bamboo.

\begin{tabular}{ccccccccc}
\hline Parameters & $\begin{array}{c}\text { Control } \\
\text { (Blank)-C }\end{array}$ & BTZ-C & NZnO-C & B3Z1-C & B2Z1-C & B1Z1-C & B1Z-C 2 & B1Z3-C \\
\hline$T(\mathrm{~h})$ & 50 & 400 & 50 & 300 & $500^{\mathrm{a}}$ & 450 & 300 & 200 \\
$\Delta T(\mathrm{~h})$ & - & - & - & 7.5 & 236.67 & 225 & 153.33 & 82.5 \\
\hline
\end{tabular}

${ }^{\mathrm{a}}$ After $500 \mathrm{~h}$ of irradiation, the color difference of the underlying bamboo remained $<6 .{ }^{\mathrm{b}}$ Data from [9].

\subsection{Mechanism for the Protection of Underlying Bamboo and Free Films by UV Absorbers}

\subsubsection{SEM Imaging of Free Films}

Figure 5 shows SEM images of different film formulations before and after aging. Large cracks were observed in the coatings without UV absorbers after aging (Figure 5 control), indicating that the polymer binders degraded. The high efficiency of BTZ toward reducing photo-oxidation and the accompanying change in the elastic properties of the acrylic binder [13] was demonstrated, despite the presence of very small cracks in the aged film. NZnO aggregated slightly in both the unaged and aged films. Crystallization was observed in unaged B3Z1, B2Z1, B1Z2, and B1Z3 films, which was reduced after aging.

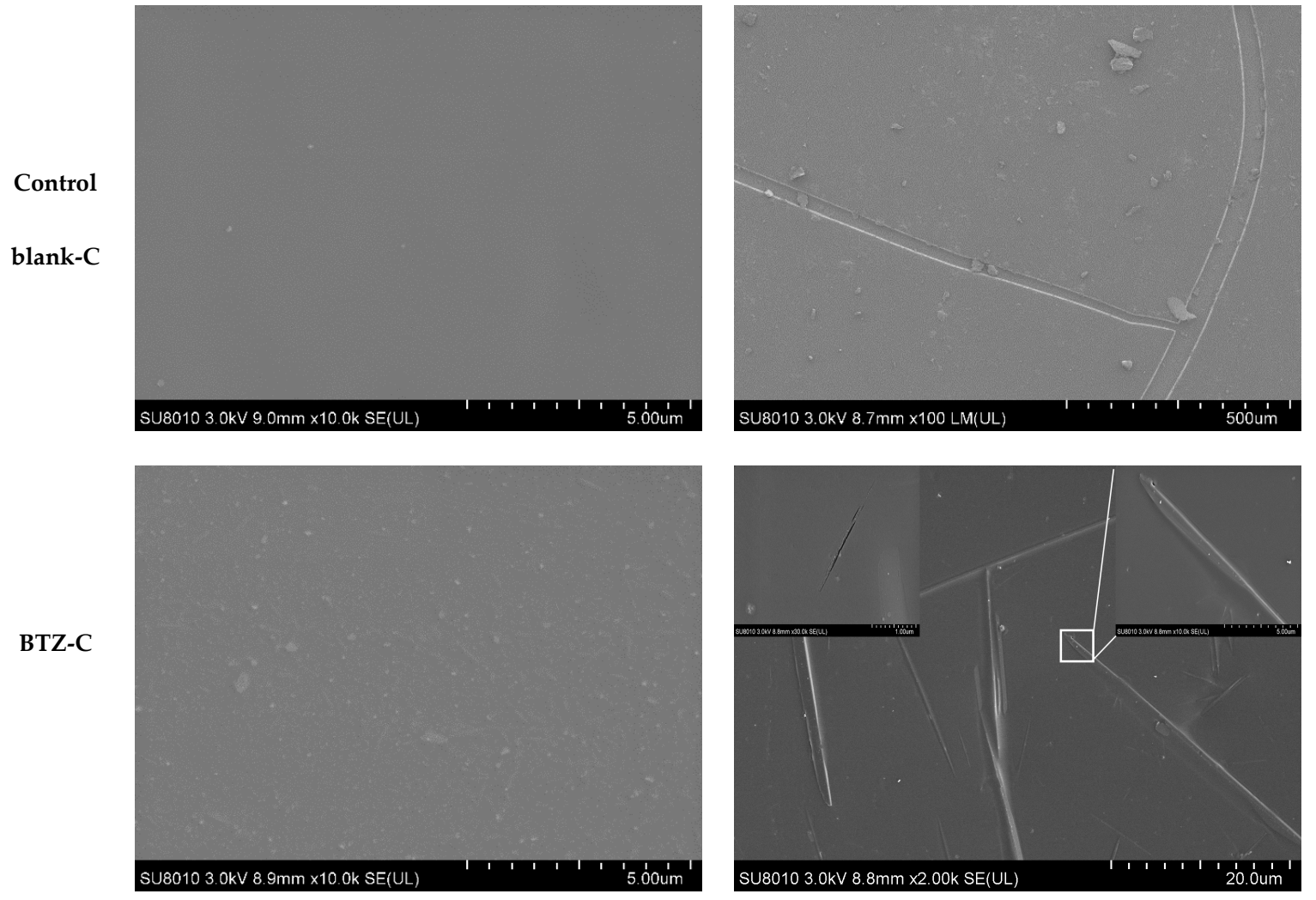

Figure 5. Cont. 

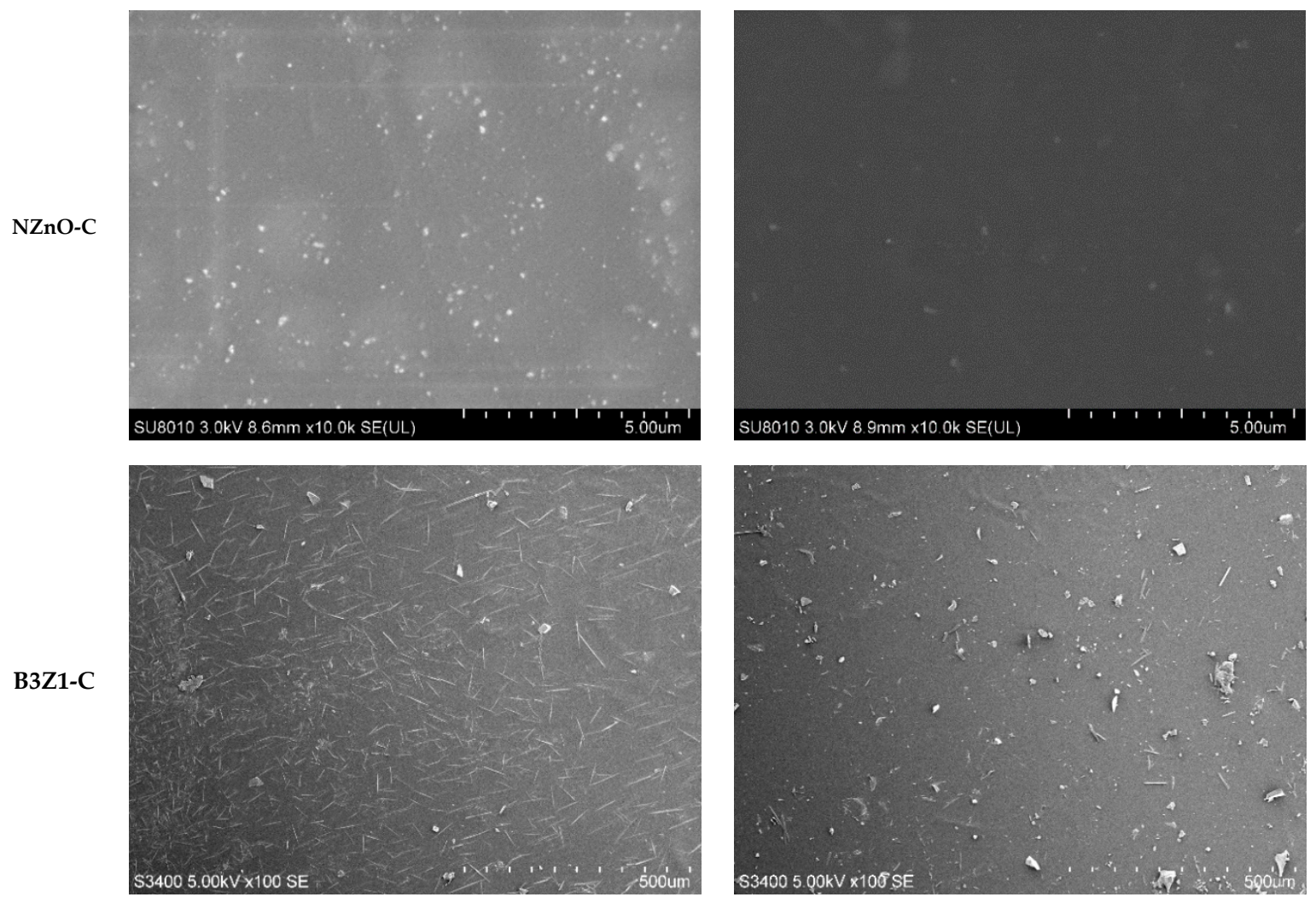

B2Z1-C
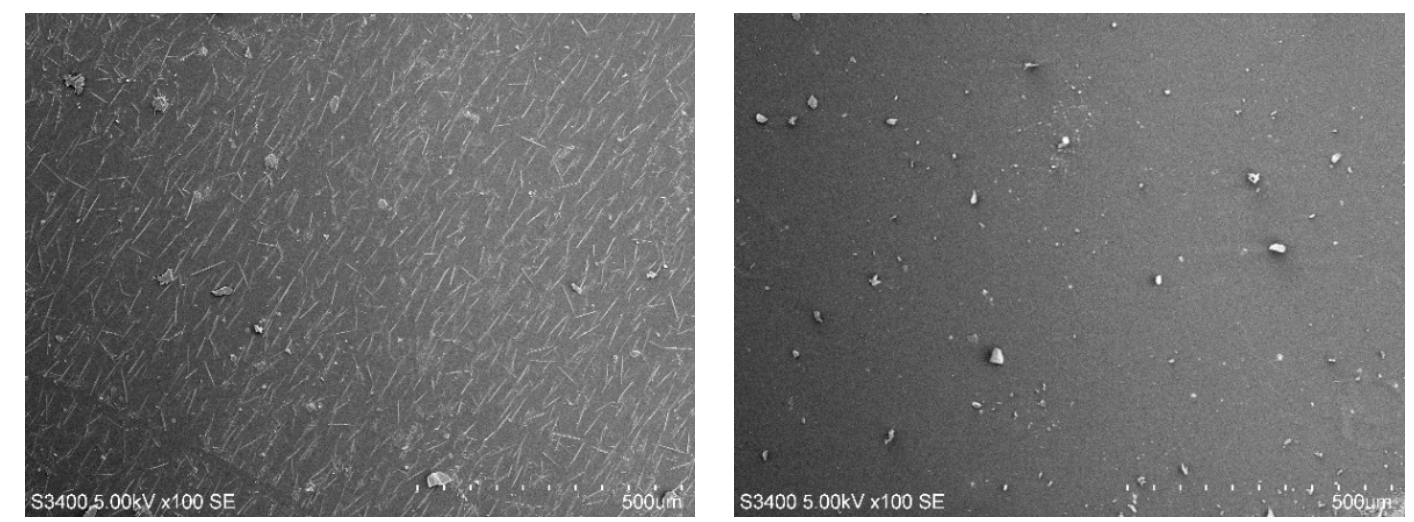

B1Z1-C
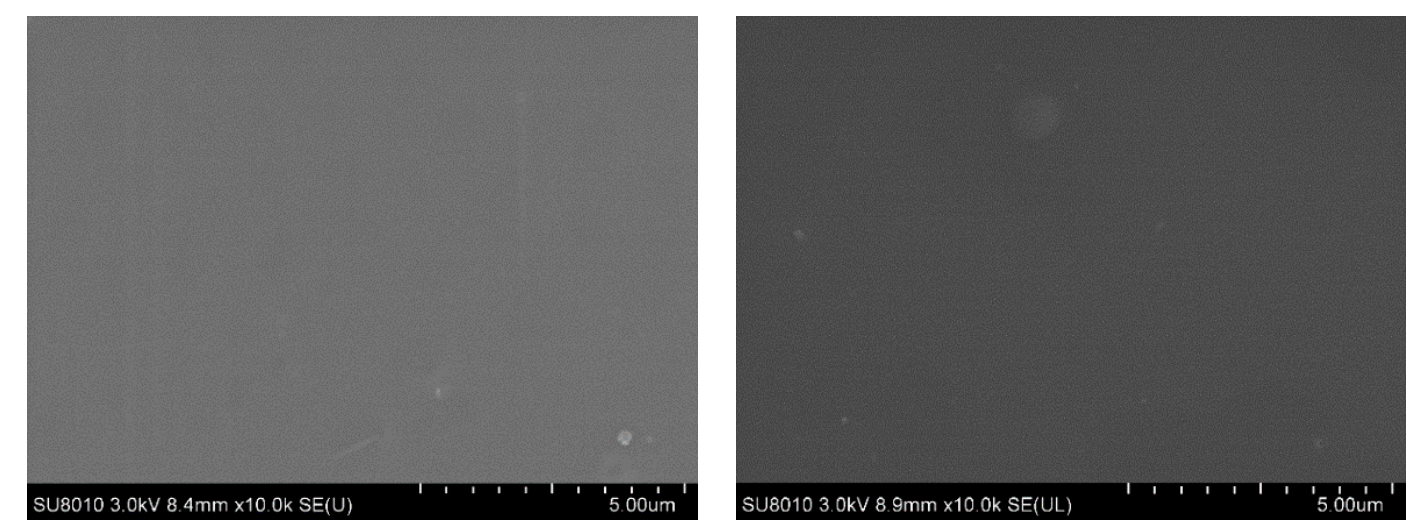

Figure 5. Cont. 
B1Z2-C
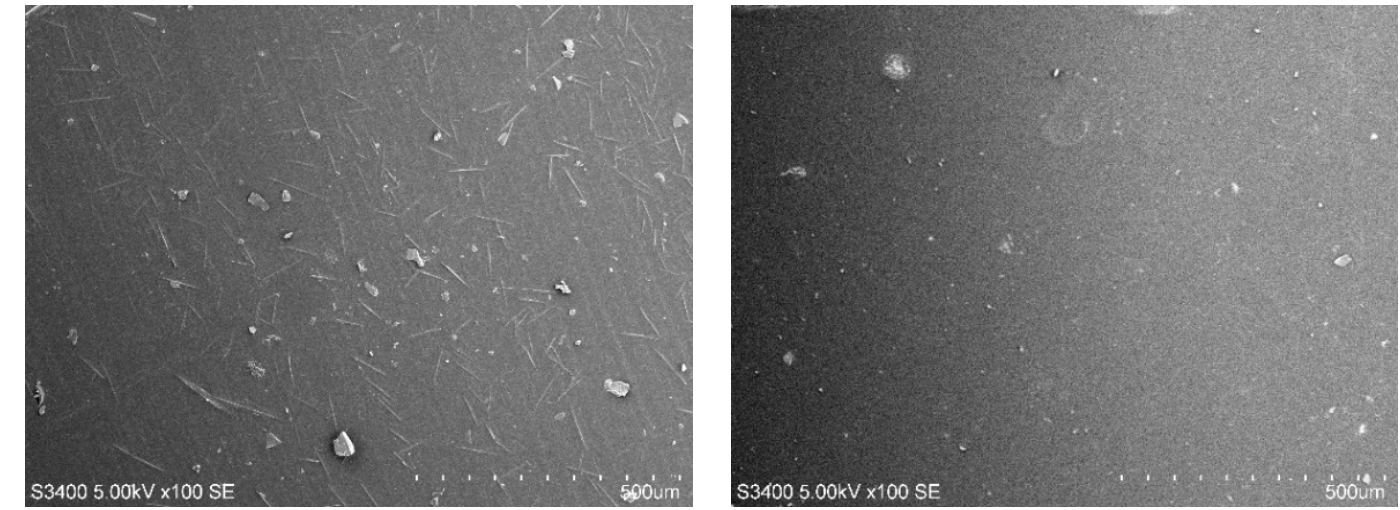

B1Z3-C
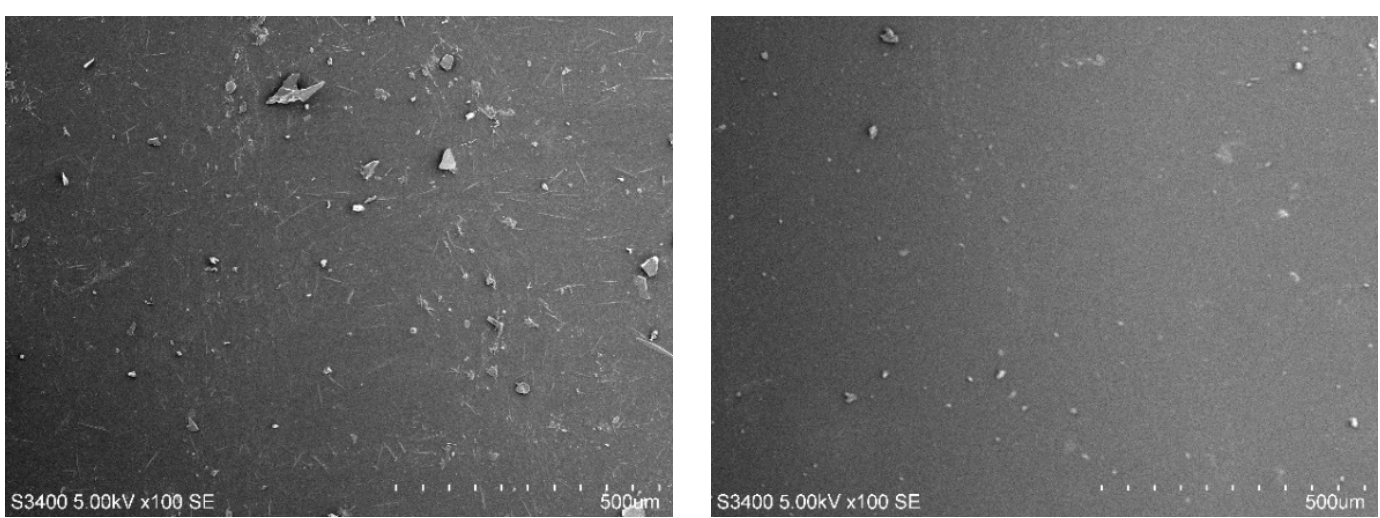

Figure 5. SEM images of the films with different formulations before and after aging.

\subsubsection{Wettability of Free Films}

Figure 6 shows the dynamic contact angles of deionized water as a function of time for different film formulations. Clearly, the contact angle on the control (blank) coating was between those of the two- and single-component UV absorber films. Table 3 reveals that the mean values of the initial and equilibrium contact angles of deionized water on the single-component $U V$ absorber films were higher than those of the two-component UV absorber films, while the mean $K$-values showed the opposite trend. The initial and equilibrium contact angles of water on the NZnO film were the smallest, and the diffusion and absorption of water were the largest. This was due to the slight aggregation of $\mathrm{NZnO}$ (Figure 5), which resulted in incomplete coverage by the acrylic binder. The rough surface enhanced the wettability of the film, making the deionized water spread faster. The contact angles of deionized water on the two-component UV absorber film surfaces were $>50^{\circ}$ within 90 frames, and the $K$-values were slightly less than that of the control film, indicating that these films possessed good hydrophobicity. Adding BTZ can be inferred to facilitate the uniform dispersion of nanoparticles in the films, thus promoting hydrophobicity [35]. Coatings that are highly hydrophobic protect bamboo better when outdoors, because the erosion caused by water accelerates photodegradation [6]. Poorly hydrophobic coatings can therefore lead to altered physical dimensions of the bamboo, causing the coating to fail, blister, and delaminate [36]. 


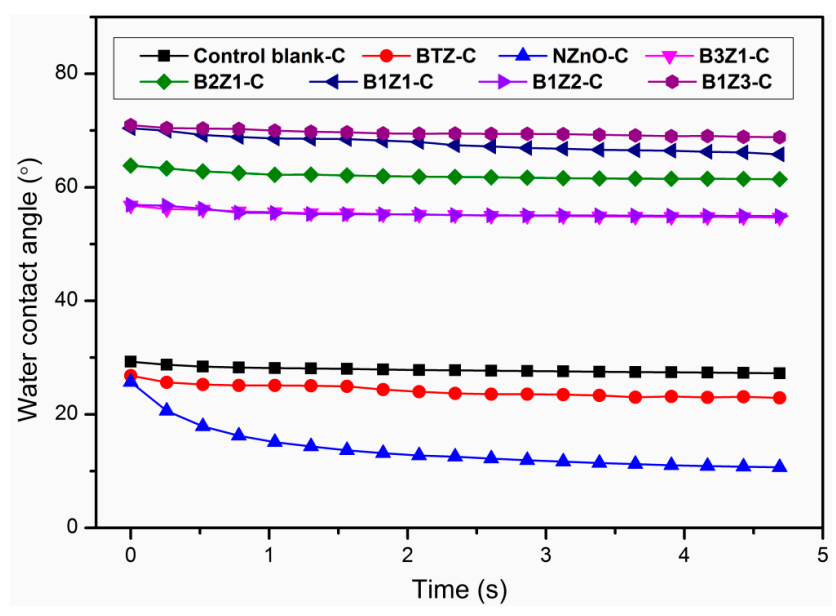

Figure 6. Time dependence of dynamic contact angle of deionized water on film surfaces.

Table 3. Initial and equilibrium contact angles and $K$-values of deionized water on film surfaces.

\begin{tabular}{cccc}
\hline Coating Films & $\theta_{\mathbf{i}}$ & $\theta_{\mathbf{e}}$ & K-Value \\
\hline Control (blank)-C & 29.27 & 27.53 & 0.0032 \\
BTZ-C & 26.83 & 24.98 & 0.0122 \\
NZnO-C & 25.68 & 11.59 & 0.0477 \\
B3Z1-C & 56.81 & 55.09 & 0.0021 \\
B2Z1-C & 63.83 & 61.52 & 0.0019 \\
B1Z1-C & 70.41 & 65.98 & 0.0017 \\
B1Z2-C & 56.91 & 54.88 & 0.0016 \\
B1Z3-C & 70.96 & 69.22 & 0.0012 \\
\hline
\end{tabular}

\subsubsection{UV-vis Spectroscopic Analysis of Free Films}

Figure 7 shows the UV-vis spectra of the eight different film formulations acquired during accelerated aging. The control film (control blank-C) exhibited stable light absorption only at $\lambda<300 \mathrm{~nm}$, featuring an acrylic resin absorption peak at $259 \mathrm{~nm}$. The films with the same concentrations of either solely BTZ or NZnO provided both advantages and disadvantages for the absorption of UV and visible light. The absorption capacity of BTZ in the UV region was derived from two strong absorption peaks at 305 and $357 \mathrm{~nm}$, which increased with increasing concentration [12]. However, photo-oxidation and decomposition of BTZ led to a decrease in UV absorption and an increase in visible light absorption, especially during the early stages of UV irradiation (Figure 7, BTZ-C). Owing to the changes in absorbance of the acrylic resin upon UV irradiation and non-decomposition associated with inorganic oxidation of $\mathrm{NZnO}$, the absorbance of the $\mathrm{NZnO}$ film in the $\mathrm{UV}$ and visible regions was extremely stable (Figure 7, NZnO-C). The amount of NZnO loaded in the NZnO-C film was $0.375 \mathrm{~g} / \mathrm{m}^{2}$, which was far lower than the amount of $\mathrm{NZnO}$ required to block $>99 \%$ UV radiation $\left(2.0 \mathrm{~g} / \mathrm{m}^{2}\right)$ [15]. Unfortunately, this coating became hazy after absorbing visible light because of the high refractive index of zinc oxide $\left(n_{(\mathrm{ZnO})}=1.9\right)$. To take full advantage of these two different $\mathrm{UV}$ absorbers while minimizing their disadvantages, we studied different ratios of two-component $U V$ absorber coatings while maintaining a total of $3 \mathrm{wt} \%$ for the UV absorbers in the formulations, which yielded positive results [9]. Figure 7 demonstrates that the films with different proportions of BTZ-NZnO showed the characteristic absorption peak of BTZ in the UV region. Increasing the $\mathrm{NZnO}$ content resulted in a hazier coating and, more importantly, the presence of $\mathrm{NZnO}$ in the various $\mathrm{BTZ}-\mathrm{NZnO}$ coatings effectively reduced the ability of the coating to block or absorb UV light, especially in the B1Z3 film (Figure 7, B1Z3-C). 
Figure 8 further shows that the mean absorbance of different films varied with the UV irradiation time in the $280-400 \mathrm{~nm}$ region. The UV-absorber-free film (control blank-C) could hardly absorb UV light, but long-term UV irradiation had little effect on its absorbance. Acrylic resin is considered a suitable binder for transparent coatings, due to its excellent UV resistance and absorption in the visible region. However, with prolonged UV irradiation time, the absorbance of coatings containing UV absorber(s) decreased to varying degrees. The absorbance of the BTZ film decreased most rapidly and severely, especially during the early stage of UV irradiation $(<200 \mathrm{~h})$, showing an exponential downward trend (Table 4). Changes in the absorbance of the BTZ film resulted in a higher standard deviation, indicative of greater variability in aging-induced BTZ degradation. In contrast, the $\mathrm{NZnO}$ coating absorbed the lowest amount of UV light of all the films containing UV absorber(s), but remarkable absorbance retention was observed because it does not decompose. For the two-component UV absorber coatings, absorbance decreased linearly with increasing irradiation time at a slower rate (Table 4), which indicated that the photo-oxidation and decomposition of BTZ was inhibited by adding $\mathrm{NZnO}$. When the relative amount of BTZ exceeded $50 \%$ (and $\mathrm{NZnO}$ is $<50 \%$ ), the two-component UV absorber films could absorb more UV light than the single-component films containing either BTZ or $\mathrm{NZnO}$ after $50 \mathrm{~h}$ of aging. The UV absorbance of two-component $\mathrm{UV}$ absorber films was determined from the relative amount of BTZ, whose degradation could be inhibited during the entire aging period studied here when $\mathrm{NZnO}$ was present in the film formulation.
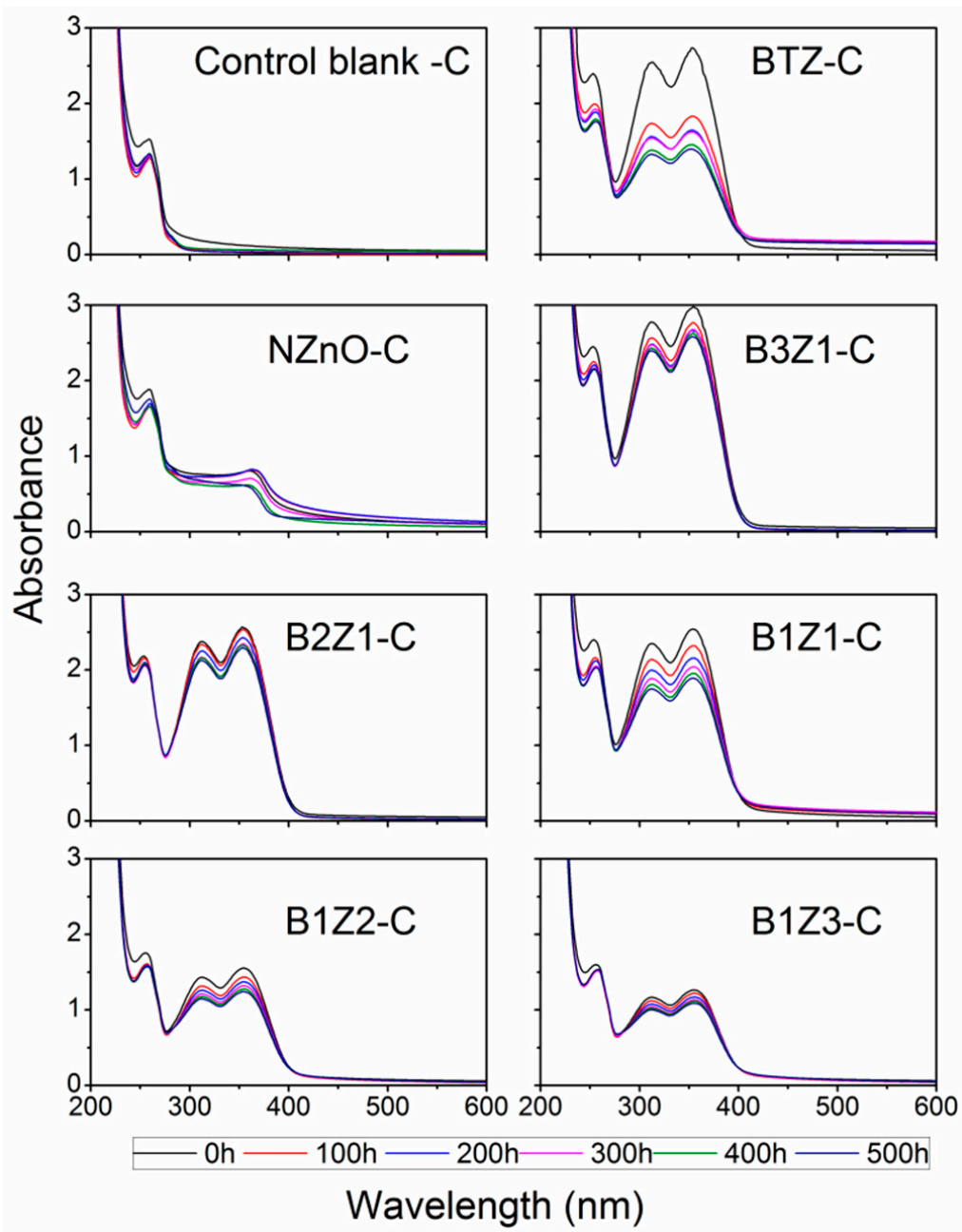

Figure 7. Aging-time-dependent UV-vis spectra of different film formulations. 


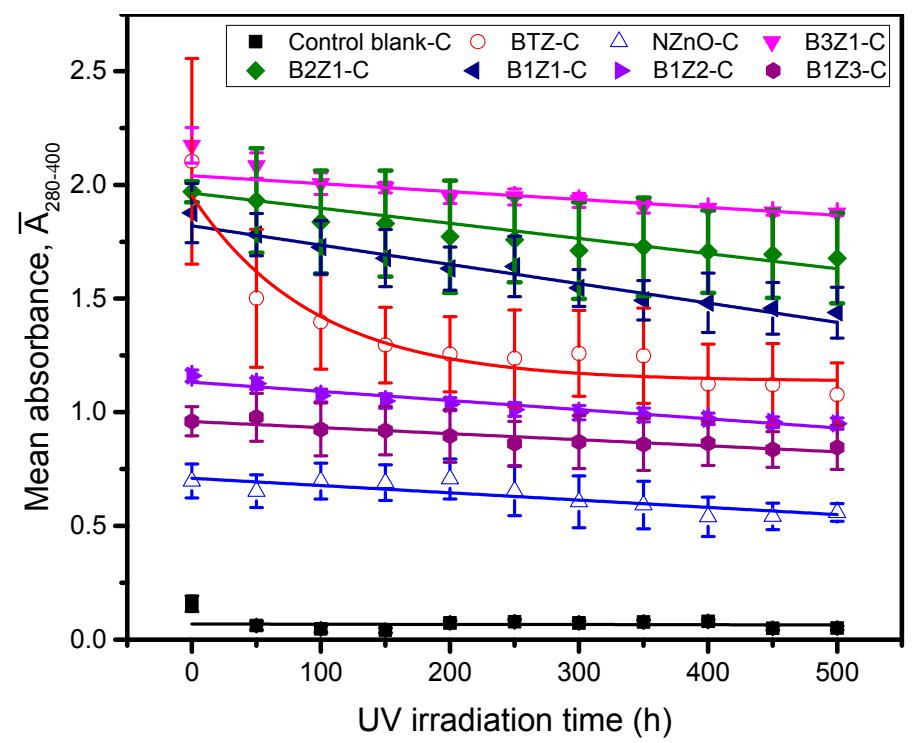

Figure 8. Changes in the average UV absorbance of BTZ-NZnO films containing different BTZ-NZnO ratios.

Table 4. Fit information of the mean absorbance of free films with increasing aging time.

\begin{tabular}{cc}
\hline Coating Formulation & Fit Information \\
\hline Control (blank)-C & $\mathrm{Y}=-8.748 \times 10^{-6} \mathrm{X}+0.069, \mathrm{R}^{2}=0.00469$ \\
BTZ-C & $\mathrm{Y}=0.816 \mathrm{exp}(-\mathrm{X} / 94.915)+1.137, \mathrm{R}^{2}=0.866$ \\
NznO-C & $\mathrm{Y}=-3.198 \times 10^{-4} \mathrm{X}+0.710, \mathrm{R}^{2}=0.831$ \\
B3Z1-C & $\mathrm{Y}=-3.472 \times 10^{-4} \mathrm{X}+2.040, \mathrm{R}^{2}=0.873$ \\
B2Z1-C & $\mathrm{Y}=-6.658 \times 10^{-4} \mathrm{X}+1.964, \mathrm{R}^{2}=0.953$ \\
B1Z1-C & $\mathrm{Y}=-8.498 \times 10^{-4} \mathrm{X}+1.820, \mathrm{R}^{2}=0.955$ \\
B1Z2-C & $\mathrm{Y}=-4.023 \times 10^{-4} \mathrm{X}+1.132, \mathrm{R}^{2}=0.937$ \\
B1Z3-C & $\mathrm{Y}=-2.667 \times 10^{-4} \mathrm{X}+0.959, \mathrm{R}^{2}=0.900$ \\
\hline
\end{tabular}

\subsubsection{FTIR-ATR Analysis of Free Films}

The FTIR-ATR spectra of the films in the region between 1800 and $800 \mathrm{~cm}^{-1}$ after accelerated aging are presented in Figure 9. For the control film, bands attributed to vibrations of polyacrylate were identified $[14,37]$ The characteristic absorbance of polyacrylate was maintained in the spectra of all of the UV-absorber-containing films. A strong band at $1725 \mathrm{~cm}^{-1}$ was assigned to the $\mathrm{C}=\mathrm{O}$ stretching vibration, whereas the bands centered at 1453 and $1383 \mathrm{~cm}^{-1}$ corresponded to the $-\mathrm{C}-\mathrm{H}$ asymmetric and symmetric deformation vibrations of $-\mathrm{CH}_{2}$ and $-\mathrm{CH}_{3}$, respectively [14]. The band at $1160 \mathrm{~cm}^{-1}$ was associated with $\mathrm{C}-\mathrm{O}$ stretching. The small peaks that appeared at 877 and $598 \mathrm{~cm}^{-1}$ in BTZ-containing films were mainly due to BTZ [12].

The intensities of three selected IR bands are shown in Table 5. The intensity of the main carbonyl peak at $1725 \mathrm{~cm}^{-1}$ changed, indicating that $\mathrm{UV}$ irradiation modified the $\mathrm{C}=\mathrm{O}$ bonds in acrylic coatings. The intensity of the bands at $1725 \mathrm{~cm}^{-1}$ in the control film decreased after aging. Two reasons can explain this change: (1) Polyacrylate photo-oxidized during the photodegradation of the clear coatings, which may have been due to abstraction of $\mathrm{CO}_{2}$ [14], and (2) UV-induced crosslinking of acrylates reduced the number of carbonyl groups present [14]. A related study found that adding BTZ to coatings may induce the decomposition of ester groups [11]. Consistent with a previous study [13], films containing only BTZ were very efficient at inhibiting the photo-oxidation of the acrylic binder. For the $\mathrm{NZnO}$ films, photocatalytic decomposition of polyacrylate may have occurred at the hydroxyl groups on the $\mathrm{NZnO}$ surface due to the photocatalytic properties of $\mathrm{NZnO}$ [37], which depend greatly on the amount of $\mathrm{NZnO}$ present [14]. The influence of $\mathrm{NZnO}$ combined with embedded BTZ on the photocatalytic activity of $\mathrm{NZnO}$ in the two-component $\mathrm{UV}$ absorber films should thus be considered. The decreased intensity of the $\mathrm{C}-\mathrm{O}$ bands centered at $1160 \mathrm{~cm}^{-1}$ for the ester copolymer in combination 
with the increased intensity of $\mathrm{C}-\mathrm{H}$ bands centered at $995 \mathrm{~cm}^{-1}$ suggested that scission of acrylate side chains and of methacrylate main chains occurred throughout the degradation process [14]. In the BTZ-NZnO films, BTZ physically adsorbed onto the surface of $\mathrm{NZnO}$ [38], forming a coordinate covalent bond between the embedded $\mathrm{BTZ}$ and $\mathrm{NZnO}$ [39], which may have reduced the photocatalytic activity of the latter [17].

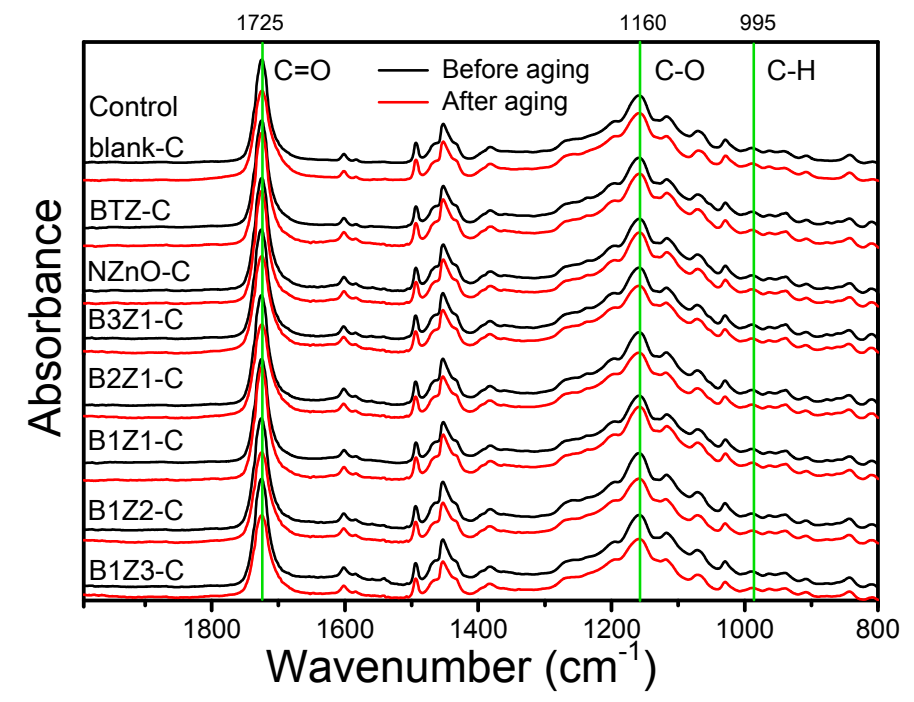

Figure 9. Changes in FTIR-ATR spectra of different film formulations in the region of $1800-800 \mathrm{~cm}^{-1}$.

Table 5. Changes in the intensity of the bands at 1725, 1160 and $995 \mathrm{~cm}^{-1}$ after $500 \mathrm{~h}$ of aging of the films.

\begin{tabular}{ccccccc}
\hline \multirow{2}{*}{$\begin{array}{c}\text { Coating } \\
\text { Formulation }\end{array}$} & \multicolumn{2}{c}{$\mathbf{1 7 2 5} \mathbf{~ c m}^{\mathbf{- 1}}$} & \multicolumn{2}{c}{$\mathbf{1 1 6 0} \mathbf{~ c m}^{-\mathbf{1}}$} & \multicolumn{2}{c}{$\mathbf{9 9 5} \mathbf{~ c m}^{\mathbf{- 1}}$} \\
\cline { 2 - 7 } & Before Aging & After Aging & Before Aging & After Aging & Before Aging & After Aging \\
\hline Control blank-C & $12.713 \pm 0.032$ & $7.430 \pm 0.119$ & $2.987 \pm 0.007$ & $1.938 \pm 0.601$ & $0.260 \pm 0.002$ & $0.174 \pm 0.048$ \\
BTZ-C & $12.177 \pm 0.338$ & $10.370 \pm 0.257$ & $2.821 \pm 0.075$ & $2.386 \pm 0.035$ & $0.263 \pm 0.006$ & $0.210 \pm 0.003$ \\
NZnO-C & $10.223 \pm 0.909$ & $11.009 \pm 0.159$ & $2.378 \pm 0.224$ & $2.627 \pm 0.009$ & $0.210 \pm 0.019$ & $0.232 \pm 0.002$ \\
B3Z1-C & $8.504 \pm 0.471$ & $6.200 \pm 0.692$ & $1.952 \pm 0.165$ & $1.265 \pm 0.162$ & $0.160 \pm 0.052$ & $0.113 \pm 0.011$ \\
B2Z1-C & $8.867 \pm 0.332$ & $5.878 \pm 0.434$ & $2.087 \pm 0.062$ & $1.271 \pm 0.092$ & $0.189 \pm 0.011$ & $0.109 \pm 0.007$ \\
B1Z1-C & $10.667 \pm 0.225$ & $11.164 \pm 0.193$ & $2.278 \pm 0.702$ & $2.627 \pm 0.011$ & $0.244 \pm 0.002$ & $0.231 \pm 0.001$ \\
B1Z2-C & $8.627 \pm 0.781$ & $4.775 \pm 0.485$ & $2.164 \pm 0.231$ & $1.179 \pm 0.124$ & $0.154 \pm 0.016$ & $0.095 \pm 0.010$ \\
B1Z3-C & $8.551 \pm 0.425$ & $4.371 \pm 0.523$ & $2.084 \pm 0.138$ & $1.082 \pm 0.154$ & $0.175 \pm 0.014$ & $0.089 \pm 0.012$ \\
\hline
\end{tabular}

\section{Conclusions}

In this study, the photostabilizing efficiency of acrylic-based bamboo exterior coatings containing $\mathrm{BTZ}$ and $\mathrm{NZnO}$ was evaluated. We found that BTZ-containing films led to less photodegradation of the bamboo substrates and more efficiently inhibited photodiscoloration than those containing only NZnO. After $500 \mathrm{~h}$ of UV irradiation, coating formulations containing a combination of $2 \mathrm{wt} \%$ BTZ and $1 \mathrm{wt} \% \mathrm{NZnO}$ showed the best performance for color stabilization of the bamboo due to UV irradiation. Furthermore, a synergistic effect was observed in the BTZ-NZnO films. In these films, the degradation of BTZ was considerably reduced, the ability to absorb UV light and inhibit acrylic binder cracking was retained, the aggregation and photocatalytic activity of $\mathrm{NZnO}$ decreased, and hydrophobicity was enhanced. These findings confirmed the potential of photostable formulations that can be applied generally to the development of coatings, thus offering abundant opportunities to exploit the complementary and mutually reinforced properties of these components in the design of a novel class of UV-shielding, transparent materials. Furthermore, the protection afforded by highly hydrophobic UV-shielding coating materials can be extended from bamboo to various wood products, including bamboo- and wood-based materials, to better withstand outdoor conditions. 
Author Contributions: Conceptualization, F.R. and N.L.; Methodology, F.R.; Software, X.X.; Validation, Y.C. and N.L.; Formal Analysis, F.R. and Y.Z.; Investigation, Y.Z., M.B. and Z.Z.; Resources, Y.Z. and W.Y.; Data Curation, Y.B.; Writing-Original Draft Preparation, F.R.; Writing—Review and Editing, F.R. and N.L.; Visualization, F.R.; Supervision, Y.C.; Project Administration, Y.C.; Funding Acquisition, Y.C. and N.L.

Funding: This research was funded by the Fundamental Research Funds for the Central Non-profit Research Institution of CAF (CAFYBB2018MB008) and the National Key Research and Development Program of China (2016YFD0600904).

Acknowledgments: The authors wish to thank Liu Qiongxia and Li Xiaoyan for experimental assistance.

Conflicts of Interest: There are no conflicts to declare.

\section{References}

1. Wang, X.; Ren, H. Comparative study of the photo-discoloration of moso bamboo (Phyllostachys pubescens Mazel) and two wood species. Appl. Surf. Sci. 2008, 254, 7029-7034. [CrossRef]

2. Rao, F.; Chen, Y.; Li, N.; Zhao, X.; Bao, Y.; Wu, Z.; Ren, D.; Xu, J.; Cai, H. Preparation and Characterization of Outdoor Bamboo- Fiber-Reinforced Composites with Different Densities. BioResources 2017, 12, 6789-6811. [CrossRef]

3. Wang, X.Q.; Ren, H.Q. Surface deterioration of moso bamboo (Phyllostachys pubescens) induced by exposure to artificial sunlight. J. Wood Sci. 2009, 55, 47-52. [CrossRef]

4. Kim, Y.S.; Lee, K.H.; Kim, J.S. Weathering characteristics of bamboo (Phyllostachys puberscence) exposed to outdoors for one year. J. Wood Sci. 2016, 62, 332-338. [CrossRef]

5. Zhu, R.; Zhang, Y.; Yu, W. Outdoor exposure tests of bamboo-fiber reinforced composite: evaluation of the physical and mechanical properties after two years. Eur. J. Wood Wood Prod. 2015, 73, 275-278. [CrossRef]

6. Evans, P.; Mathews, M.J.C.B.; Schmalzl, K.; Ayer, S.; Kiguchi, M.; Kataoka, Y. Chapter 14 Weathering and Surface Protection of Wood; William Andrew Publishing: Norwich, NY, USA, 2005.

7. Li, N.; Chen, Y.; Yu, H.; Xiong, F.; Yu, W.; Bao, M.; Wu, Z.; Huang, C.; Rao, F.; Li, J.; et al. Evaluation of optical properties and chemical structure changes in enzymatic hydrolysis lignin during heat treatment. RSC Adv. 2017, 7, 20760-20765. [CrossRef]

8. Cogulet, A.; Blanchet, P.; Landry, V. Wood degradation under UV irradiation: A lignin characterization. J. Photochem. Photobiol. B Biol. 2016, 158, 184-191. [CrossRef] [PubMed]

9. Rao, F.; Chen, Y.; Zhao, X.; Cai, H.; Li, N.; Bao, Y. Enhancement of bamboo surface photostability by application of clear coatings containing a combination of organic/inorganic UV absorbers. Prog. Org. Coat. 2018, 124, 314-320. [CrossRef]

10. Forsthuber, B.; Schaller, C.; Grull, G. Evaluation of the photo stabilising efficiency of clear coatings comprising organic UV absorbers and mineral UV screeners on wood surfaces. Wood Sci. Technol. 2013, 47, 281-297. [CrossRef]

11. Li, N.; Bao, M.; Rao, F.; Shu, Y.; Huang, C.; Huang, Z.; Chen, Y.; Bao, Y.; Guo, R.; Xiu, C. Improvement of surface photostability of bamboo scrimber by application of organic UV absorber coatings. J. Wood Sci. 2019, 65. [CrossRef]

12. Li, N.; Chen, Y.; Bao, Y.; Zhang, Z.; Wu, Z.; Chen, Z. Evaluation of UV-permeability and photo-oxidisability of organic ultraviolet radiation-absorbing coatings. Appl. Surf. Sci. 2015, 332, 186-191. [CrossRef]

13. Forsthuber, B.; Müller, U.; Teischinger, A.; Grüll, G. Chemical and mechanical changes during photooxidation of an acrylic clear wood coat and its prevention using UV absorber and micronized $\mathrm{TiO}_{2}$. Polym. Degrad. Stab. 2013, 98, 1329-1338. [CrossRef]

14. Forsthuber, B.; Grüll, G. The effects of HALS in the prevention of photo-degradation of acrylic clear topcoats and wooden surfaces. Polym. Degrad. Stab. 2010, 95, 746-755. [CrossRef]

15. Lowry, M.S.; Hubble, D.R.; Wressell, A.L.; Vratsanos, M.S.; Pepe, F.R.; Hegedus, C.R. Assessment of UV-permeability in nano-ZnO filled coatings via high throughput experimentation. J. Coat. Technol. Res. 2008, 5, 233-239. [CrossRef]

16. Auclair, N.; Riedl, B.; Blanchard, V.; Blanchet, P. Improvement of photoprotection of wood coatings by using inorganic nanoparticles as ultraviolet absorbers. For. Prod. J. 2011, 61, 20-27. [CrossRef]

17. Hong, R.Y.; Li, J.H.; Chen, L.L.; Liu, D.Q.; Li, H.Z.; Zheng, Y.; Ding, J. Synthesis, surface modification and photocatalytic property of $\mathrm{ZnO}$ nanoparticles. Powder Technol. 2009, 189, 426-432. [CrossRef] 
18. Vlad, M.; Riedl, B.; Blanchet, P. Enhancing the performance of exterior waterborne coatings for wood by inorganic nanosized UV absorbers. Prog. Org. Coat. 2010, 69, 432-441. [CrossRef]

19. Vu, P.G.; Dung, N.T.; Duong, N.T.; Truc, T.A.; Thanh, D.T.M.; Hoang, T.; Van Truoc, B.; Hang, T.T.X.; Olivier, M. Effect of silane modified nano $\mathrm{ZnO}$ on UV degradation of polyurethane coatings. Prog. Org. Coat. 2014, 79, 68-74.

20. Nair, S.; Nagarajappa, G.B.; Pandey, K.K. UV stabilization of wood by nano metal oxides dispersed in propylene glycol. J. Photochem. Photobiol. B Biol. 2018, 183, 1-10. [CrossRef] [PubMed]

21. Pánek, M.; Oberhofnerová, E.; Zeidler, A.; Šedivka, P. Efficacy of hydrophobic coatings in protecting oak wood surfaces during accelerated weathering. Coatings 2017, 7, 172. [CrossRef]

22. Pánek, M.; Oberhofnerová, E.; Hýsek, Š.; Šedivka, P.; Zeidler, A. Colour stabilization of oak, spruce, larch and douglas fir heartwood treated with mixtures of nanoparticle dispersions and UV-stabilizers after exposure to UV and VIS-radiation. Materials (Basel) 2018, 11, 1653. [CrossRef] [PubMed]

23. Chang, S.-T.; Chou, P.-L. Photo-discoloration of UV-curable acrylic coatings and the underlying wood. Polym. Degrad. Stab. 1999, 63, 435-439. [CrossRef]

24. Chou, P.L.; Chang, H.T.; Yeh, T.F.; Chang, S.T. Characterizing the conservation effect of clear coatings on photodegradation of wood. Bioresour. Technol. 2008, 99, 1073-1079. [CrossRef] [PubMed]

25. Chang, S.T.; Chou, P.L. Photodiscoloration inhibition of wood coated with UV-curable acrylic clear coatings and its elucidation. Polym. Degrad. Stab. 2000, 69, 355-360. [CrossRef]

26. Yu, H.; Yu, W.; Yang, L.; Fang, C.; Xu, M. Surface Discoloration Analysis and Lignin Degradation Fragments Identification of UV-Irradiated Moso Bamboo (Phyllostachys pubescens Mazel). BioResources 2015, 10, 1617-1626. [CrossRef]

27. Shi, S.Q.; Gardner, D.J. Dynamic Adhesive Wettability of Wood. Wood Fiber Sci. 2001, 33, 58-68.

28. Huang, X.; Kocaefe, D.; Boluk, Y.; Kocaefe, Y.; Pichette, A. Effect of surface preparation on the wettability of heat-treated jack pine wood surface by different liquids. Eur. J. Wood Wood Prod. 2012, 70, 711-717. [CrossRef]

29. ASTM D 2244-07 Standard Practice for Calculation of Color Tolerances and Color Differences from Instrumentally Measured Color Coordinates; ASTM: West Conshohocken, PA, USA, 2005.

30. Liu, Y.; Fangru, X.; Jihang, H.; Hongwu, G. Photoehromic inhibition of dyed veneer covered with modified transparent film. Adv. Mater. Res. 2014, 933, 38-42. [CrossRef]

31. Temiz, A.; Terziev, N.; Jacobsen, B.; Eikenes, M. Weathering, water absorption, and durability of silicon, acetylated, and heat-treated wood. J. Appl. Polym. Sci. 2006, 102, 4506-4513. [CrossRef]

32. Gugumus, F. Possibilities and limits of synergism with light stabilizers in polyolefins 2 . UV absorbers in polyolefins. Polym. Degrad. Stab. 2002, 75, 309-320. [CrossRef]

33. Ayadi, N.; Lejeune, F.; Charrier El Bouhtoury, F.; Charrier, B.; Merlin, A. Color stability of heat-treated wood during artificial weathering. Eur. J. Wood Wood Prod. 2003, 61, 221-226. [CrossRef]

34. Popescu, C.M.; Popescu, M.C.; Vasile, C. Structural analysis of photodegraded lime wood by means of FT-IR and 2D IR correlation spectroscopy. Int. J. Biol. Macromol. 2011, 48, 667-675. [CrossRef] [PubMed]

35. Li, J.; Sun, Q.; Yao, Q.; Wang, J.; Han, S.; Jin, C. Fabrication of robust superhydrophobic bamboo based on $\mathrm{ZnO}$ nanosheet networks with improved water-, UV-, and fire-resistant properties. J. Nanomater. 2015, 2015, 1-9. [CrossRef]

36. Hayoz, P.; Peter, W.; Rogez, D. A new innovative stabilization method for the protection of natural wood. Prog. Org. Coat. 2003, 48, 297-309. [CrossRef]

37. McNeill, I.C.; Mohammed, M.H. Thermal analysis of blends of low density polyethylene, poly(ethyl acrylate) and ethylene ethyl acrylate copolymer with polydimethylsiloxane. Polym. Degrad. Stab. 1995, 50, $285-295$. [CrossRef]

38. Haacke, G.; Longordo, E.; Brinen, J.S.; Andrawes, F.F.; Campbell, B.H. Chemisorption and physical adsorption of light stabilizers on pigment and ultrafine particles in coatings. J. Coat. Technol. 1999, 71, 87-94. [CrossRef]

39. Mahltig, B.; Böttcher, H.; Rauch, K.; Dieckmann, U.; Nitsche, R.; Fritz, T. Optimized UV protecting coatings by combination of organic and inorganic UV absorbers. Thin Solid Films 2005, 485, 108-114. [CrossRef]

(C) 2019 by the authors. Licensee MDPI, Basel, Switzerland. This article is an open access article distributed under the terms and conditions of the Creative Commons Attribution (CC BY) license (http://creativecommons.org/licenses/by/4.0/). 